\title{
Influence of a variant angina on the results of percutaneous transluminal coronary angioplasty
}

\author{
F LEISCH, W SCHÜTZENBERGER, K KERSCHNER, W HERBINGER
}

From the First Department of Medicine (Cardiology), General Hospital, Linz, Austria

SUMMARY Nineteen $(86 \%)$ of 22 patients with variant angina and important coronary stenoses $(>60 \%$ ) had successful percutaneous transluminal coronary angioplasty. The acute complications in two patients were not caused by coronary spasms but by dissection with disturbance of perfusion. One of these two patients required a coronary bypass graft; the other was treated conservatively. Myocardial infarction developed in both patients. Despite long term administration of nifedipine (30-80 mg daily), restenoses occurred within six months (on average after 10 weeks) in nine patients with symptoms and one without. In four patients the restenoses exceeded the degree of stenosis before angioplasty. Five patients were revascularised by surgical means. Vessels in three out of four patients were later successfully dilated. After a mean period of observation of 24 months (6-51 months) 18 of the 19 patients are symptom free and do not require medication.

The results confirm that angioplasty is an effective method of treating patients with variant angina and important coronary stenoses. The problem of the high frequency of restenosis, however, remains unresolved.

Coronary spasm is important in the various ischaemic syndromes that occur in coronary heart disease. ${ }^{1-3}$ The clinical spectrum ranges from exercise induced spasm to angina occurring exclusively at rest. Angiography shows normal to very considerably stenosed coronary vessels. ${ }^{34}$

Patients with coronary spasms are usually successfully treated with calcium antagonists. ${ }^{5}$ The results of medical treatment are excellent when the vasospastic component predominates. ${ }^{46}$ Revascularisation must be considered, however, in patients with considerable stenoses. ${ }^{478}$ Some centres report good results with bypass surgery in variant angina ${ }^{89}$; others do not ${ }^{1011}$ or they recommend plexectomy in addition. ${ }^{7}$

Percutaneous transluminal coronary angioplasty is a method of revascularisation that only slightly inconveniences the patient. ${ }^{12}$ Angioplasty has so far been regarded as dangerous or indeed as contraindicated in patients with vasospastic angina because of the danger of intensifying the tendency to spasm

Requests for reprints to Dr F Leisch, 1 Medizinische Abteilung, Allgemeines Krankenhaus, Krankenhausstrasse 9, A-4020 Linz, Austria.

Accepted for publication 23 June 1986 by mechanical irritation and because it is assumed that spasms will continue to cause anginal symptoms despite elimination of the organic stenosis. ${ }^{13.14}$ When there are important fixed stenosis, however, slight spasm could produce constriction leading to a perfusion defect. ${ }^{1516}$ For this reason we have studied the success rate of angioplasty carried out because of critical coronary stenoses in patients with superimposed coronary spasm caused by variant angina. We report on the short term and long term results in 22 patients.

\section{Patients and methods}

Percutaneous transluminal coronary angioplasty was carried out in 265 patients from November 1980 to April 1985. In $22(8 \%)$ patients variant angina had been diagnosed before the procedure. Variant angina was defined as a spontaneous attack of angina pectoris with reversible ST segment elevation $(>0.1 \mathrm{mV})$ without an increase in the concentrations of cardiac enzymes. Patients with impending infarct expansion were not included in this study. In 21 patients, the diagnosis could be made during the spontaneous pain attack in the 12 lead electrocardiogram and in one patient by positive 
ergometrine maleate provocation during diagnostic coronary angiography. Table 1 gives the clinical data on these patients.

Table 1 Clinical data

\begin{tabular}{ll}
\hline Data & No \\
\hline Total patients & 22 \\
Male/female & $15 / 7$ \\
Mean (SD) age (yr) (range) & $52(11)(33-74)$ \\
Duration of angina (weeks) & $6(12)$ \\
No with angina for <6 weeks & 17 \\
Previous myocardial infarction & 3 \\
Rest angina & 22 \\
Exertion angina & 19 \\
ST segment elevation: & 15 \\
$\quad$ Anterior & 7 \\
Inferior & 22 \\
Single vessel disease & 0 \\
Results of medical treatment: & 10 \\
Symptom free & 12 \\
$\quad$ Improved & Unchanged \\
\hline
\end{tabular}

Bicycle ergometry and thallium-201 scintigraphy were carried out in seven patients before and after successful angioplasty. In eight additional patients these investigations were performed only in the first week after successful angioplasty. Coronary angiography was performed by Judkins's technique. The degree of fixed coronary stenosis was calculated before and after angioplasty (after sublinqual glyceryl trinitrate $(0.8 \mathrm{mg})$ and nifedipine $(10 \mathrm{mg})$ had been given) as a mean reduction of diameter in at least two projections in end diastole. The degree of stenosis was measured independently by two of the authors using a calibrated magnifying glass. ${ }^{17}$ The same projections were always used in comparison investigations and the same vasodilators were administered to assess the degree of stenosis at follow up angiography.

\section{DETECTION OF CORONARY SPASM}

Spontaneous spasm was seen at diagnostic coronary angiography in three patients during an attack of variant angina. In nine patients we attempted to provoke spasm with serial doses of ergometrine maleate (from $0.05 \mathrm{mg}$ to a maximum of $0.2 \mathrm{mg}$ ). This provoked a positive result in seven patients but not in two. The ergometrine maleate test was deemed to be positive if it led to a complete coronary occlusion or a considerable increase in the degree of stenosis $(>20 \%$ ) with anginal symptoms or ischaemic changes in the electrocardiogram or both. The ergometrine maleate provocation test was not used in the remaining 10 patients because they had severe clinical symptoms with several attacks each day.

PERCUTANEOUS TRANSLUMINAL CORONARY ANGIOPLASTY

Angioplasty was indicated in all patients because of important coronary stenosis ( $>60 \%$ ) with treatment resistant angina pectoris. The procedure was carried out in accordance with the method developed by Gruentzig et al with surgical standby. ${ }^{12}$ After angioplasty all patients were monitored for 24 hours and the standard electrocardiogram and the heart muscle specific enzymes (NAC-creatine kinase and creatine kinase $M B$ ) were checked every six hours.

All patients received $40-80 \mathrm{mg}$ isosorbide dinitrate and 40-80 mg nifedipine daily and three patients also received $40 \mathrm{mg}$ propranolol three times a day. Patients were also treated with aspirin (1.5 $\mathrm{g} /$ day) beginning on the day before angioplasty and with $10 \mathrm{mg}$ diazepam and $20 \mathrm{mg}$ nifedipine two hours before angioplasty. An infusion of glyceryl trinitrate $(1 \cdot 2-3.0 \mathrm{mg} / \mathrm{h})$ was started before angioplasty and was continued for 24 hours.

During angioplasty heparin (10000 units), low molecular weight dextran, and intracoronary glyceryl trinitrate $(0 \cdot 2-0.4 \mathrm{mg})$ were given. After angioplasty and up to the planned follow up angiography all patients were given $30-80 \mathrm{mg}$ nifedipine daily and 14 patients also received isosorbide dinitrate (40-80 mg). Patients $1-5$ received warfarin and the remainder took $0.5 \mathrm{~g}$ of aspirin daily.

\section{FOLLOW UP}

All patients were discharged two to three days after a successful angioplasty, and they were asked to attend again after six months for an angiographic examination. The follow up examination was done earlier if angina recurred. In the subsequent years the patients were followed up every six months.

\section{Results}

PERCUTANEOUS TRANSLUMINAL CORONARY ANGIOPLASTY

Angioplasty was successful (producing a $>20 \%$ widening of the stenosis) in $19(86 \%)$ out of 22 patients (table 2). Double stenoses in the left anterior descending artery or of the circumflex artery were dilated in two patients. The mean (SD) degree of stenusis was reduced from $80(10) \%$ to $30(15) \%$, and the transstenotic systolic pressure gradient from 66 (15) $\mathrm{mm} \mathrm{Hg}$ to 19 (9) $\mathrm{mm} \mathrm{Hg}$. In one patient with a severe stenosis in the left anterior descending artery, the stenosis could not be passed with the bal-

Table 2 Results of angioplasty

\begin{tabular}{lcl}
\hline & No & $\%$ \\
\hline Successful angioplasty & $19 / 22$ & $(86)$ \\
Left anterior descending artery & $13 / 15$ & $(87)$ \\
Right coronary artery & $4 / 5$ & $(80)$ \\
Circumflex artery & $2 / 2$ & $(100)$ \\
\hline
\end{tabular}


loon. In two patients with stenosis in the proximal region of the right coronary artery, angioplasty led to dissection in the stenotic region with deterioration of perfusion and signs of ischaemia (chest pain, ST segment elevation). One patient suffered a complete occlusion and was immediately operated on, and the other patient who had maintained residual perfusion was treated conservatively. Both patients had a myocardial infarction, however. During angioplasty three patients had occlusive spasms in the stenotic region. These resolved again immediately after a repeat intracoronary dose of glyceryl trinitrate. A further patient had chest pain lasting for three hours but there was no objective evidence of ischaemia.

\section{BICYCLE ERGOMETRY AND THALLIUM-201 \\ SCINTIGRAPHY}

Two of the seven patients investigated by ergometry before angioplasty had normal exercise tolerance $(150$ or $175 \mathrm{~W})$, but five patients were restricted to $75 \mathrm{~W}$ by angina pectoris. Three patients showed exercise induced ST segment elevation and four patients showed ST segment depression. All patients had reversible thallium-201 defects in the area supplied by the stenosed coronary artery.

Immediately after the successful angioplasty reversible thallium defects were no longer seen in any of the seven patients who were tested before angioplasty. One patient continued to show ST segment depression and a further patient showed a normalisation of negative $T$ waves. None of the patients had angina pectoris and their mean (SD) exercise tolerance rose from $100(50) \mathrm{W}$ to $133(26) \mathrm{W}$.

After successful angioplasty the remaining eight patients could carry out an average of 115 (23) W exercise without angina developing. Two patients had ST segment depression but no patient had reversible ischaemia shown by the thallium-201 scintigram.

\section{ANGIOGRAPHIC FOLLOW UP (TABLE 3)}

All 19 patients in whom dilatation was suceessful were examined by angiography within six months. In eight patients the investigation had to be carried out before six months had elapsed because they had both rest and exercise angina 4-20 weeks (mean 10 weeks) after angioplasty. All eight patients showed a restenosis ( $>50 \%$ restenosis). In four patients the restenosis was more severe $(>90 \%$ ) than the original stenosis. Two of these patients had.a complete coronary occlusion. None of the patients had sustained a myocardial infarction, because there was a good collateral supply. In four patients the restenosis was equivalent to that found before angioplasty.

At a routine 6 month follow up 10 patients were symptom free and one patient had angina on exertion with occasional attacks at rest. The symptomatic patient and one symptom free patient had restenoses equivalent to the stenosis present before angioplasty. Nine symptom free patients did not show any restenosis. The rate of restenosis determined angiographically within six months was $53 \%$ (10/9).

Table 3 Recurrence after angioplasty

\begin{tabular}{ll}
\hline & No \\
\hline Restenoses (<6 months): & $10\left(53^{\circ}{ }_{\mathrm{o}}\right)$ \\
Symptomatic & 9 \\
Asymptomatic & 1 \\
More severe than before angioplasty & 4 \\
Repeat angioplasty (successful) & $3 / 4$ \\
Coronary bypass surgery & 5 \\
No restenoses (asymptomatic) & 9 \\
\hline
\end{tabular}

FOLLOW UP OBSERVATION (TABLE 3)

Four patients with severe restenoses and one patient with restenosis and aneurysm in the dilated region of the coronary artery had coronary bypass surgery within 6 months of angioplasty. Two patients had a perioperative myocardial infarction. A further four symptom free patients with restenosis had repeat angioplasty, which was successful in three patients. The patient in whom dilatation was not achieved was treated conservatively. One further patient with restenosis was also symptom free and off medication.

After a mean observation period of 24 months (6-51 months), 18 out of 19 patients with successful primary dilatation were symptom free and off medication: nine patients without restenosis, one patient with restenosis, five patients after bypass surgery, and three patients after repeat angioplasty. The remaining patient, with restenosis, is in New York Heart Association stage II.

\section{Discussion}

Although percutaneous transluminal coronary angioplasty is widely used to treat coronary stenoses irrespective of the clinical coronary syndrome, there are few reports of its use in patients with coronary stenosis and vasospastic angina. ${ }^{18-20}$ Corcos et al reported on 21 patients with variant angina in whom the diagnosis was made only after angioplasty in one third of the cases ${ }^{20}$; however, variant angina was diagnosed before dilatation in the study of Bertrand et $a l^{19}$ and in our 22 patients. Despite full medical treatment (isosorbide dinitrate, nifedipine), all our patients had symptoms: in 12 recurrent spontaneous attacks with ST segment elevation had continued and in 10 there had been a clinical improvement but they were not free of symptoms. 
The primary success rates of angioplasty in patients with variant angina are excellent and indeed they are better than the short term results reported in consecutive series. ${ }^{20}$ Dilatation was successful in $19(86 \%)$ of our 22 patients, whereas our primary success rate in the remaining 243 dilated patients was $72 \%$. Clinically important coronary spasm was seen during angioplasty in about $5 \%$ of cases. ${ }^{21}$ Very occasionally coronary spasm led to myocardial infarction or made it necessary to carry out emergency bypass surgery. ${ }^{22}$ Hence angioplasty in patients with coronary stenoses and superimposed coronary spasm appeared to be especially risky. Initial experience in a few cases, however, did not confirm that the immediate risk in these patients was increased, ${ }^{182324}$ and these results were confirmed in larger numbers of patients. ${ }^{1920}$

Although coronary spasms occurred in three of our patients during angioplasty, the complications we encountered were not caused by coronary spasms. In two patients there was a persistent disorder of perfusion caused by dissection. In one case this necessitated emergency bypass surgery and in another patient it led to a myocardial infarction. Others have not reported higher rates of complications. ${ }^{182025}$ Restenoses were reported in 13\% and $34 \%$ of two large series. ${ }^{26}{ }^{27}$ Known risk factors for restenosis include male sex, severe symptoms before angioplasty, no history of myocardial infarction, a long stenosis, and a persistent transstenotic pressure gradient of $>15 \mathrm{~mm} \mathrm{Hg}{ }^{2728}$

Particularly high rates of restenosis have been reported in patients with variant angina. Corcos et al reported restenosis in nine $(47 \%)$ out of 19 patients ${ }^{20}$ and Bertrand et al reported it in $13(40 \%)$ out of $32 .{ }^{19}$ We found restenosis at angiographic examination within six months of angioplasty in all nine patients with symptoms (eight patients with resting and exercise angina, one patient with exercise angina only) and in one symptom free patient. The rate of restenosis in these patients is more than twice that at angiographic follow up of 118 patients with stable angina $(21 \%)$. Coronary spasm alone without restenosis was not the cause of the anginal symptoms which occurred after a symptom free interval of 2-12 weeks after angioplasty in patients with symptoms. The development of more severe obstruction than had been present before angioplasty within a few weeks in four of our patients suggests that the progression of a stenosis may be accelerated by angioplasty. We do not know to what extent the stenosis would have progressed without angioplasty or whether vasospasms can be provoked by the dilatation itself.

Current experience indicates that coronary spasm rarely occurs after angioplasty in patients without variant angina ${ }^{20} 29$ and is not a major risk factor for restenosis. ${ }^{30}$ The higher frequency of restenosis and the brief occurrence of anginal symptoms after angioplasty in patients with variant angina suggest that in some cases spasm may favour the development of a restenosis. Our study does not allow us to confirm or deny the observation of Corcos et al that the restenosis rate can be significantly reduced by longer term administration of calcium antagonists. ${ }^{20}$ In our series the incidence of restenoses was $53 \%$ despite long term nifedipine treatment (30 to $80 \mathrm{mg}$ daily). In a similar study group Corcos et al found that in 14 patients receiving diltiazem $(120 \mathrm{mg}$ three times daily) after angioplasty the restenosis rate was only $21 \%(3 / 14){ }^{20}$ This difference may reflect the efficacy of the two calcium antagonists and the more severe clinical course in our patients.

Patients with variant angina have a high frequency of myocardial infarction and death in the acute phase. ${ }^{3}$ Although the outcome of patients with variant angina on appropriate treatment is reasonably good after the acute phase, even in the presence of severe coronary atherosclerosis, ${ }^{31}{ }^{32}$ only about $50 \%$ of the patients remained symptom free for at least one year. ${ }^{31}$ Angioplasty produced more of an improvement in symptoms than medical treatment alone, but we cannot compare the prognosis of patients with variant angina in the two treatment groups because the numbers of patients were small. Eighteen of our 19 patients were symptom free 24 months after angioplasty and six months after the discontinuation of calcium antagonists. Nine did not have restenosis, one had restenosis, five had had bypass sugery, and three had had repeat angioplasty. The remaining patient, with restenosis, has slight symptoms (New York Heart Association group II).

Corcos et al also found that patients with variant angina had a favourable medium term course after angioplasty. ${ }^{20}$ Within a mean observation period of 33 months there was one death and the 20 other patients were symptom free (three after bypass surgery, five after repeat angioplasty, and two on continuing calcium antagonists).

Although coronary angioplasty made a large percentage of patients symptom free, the most effective drug treatment after angioplasty in patients with variant angina remains to be determined. The value of administering higher doses of calcium antagonists must be tested in a controlled study.

\section{References}

1 Prinzmetal M, Kennamer R, Merliss R, Wada T, Bor N. Angina pectoris. I. A variant form of angina pec- 
toris. Am $\mathcal{F}$ Med 1959;27:375-88.

2 Hillis LD, Braunwald E. Coronary artery spasm. $N$ Engl f Med 1978;299:695-702.

3 Maseri A, Severi S, DeNes N, et al. "Variant" angina: one aspect of a continuous spectrum of vasospastic myocardial ischemia. Pathogenetic mechanism, estimated incidence and clinical and coronary angiographic findings in 138 patients. Am $\mathcal{f}$ Cardiol 1978;42:1019-35.

4 Leisch F, Schützenberger W, Bergmann H Jr, Kramar $R$, Herbinger W. Variant Angina. Nicht-invasive Parameter zur Erkennung der Koronarmorphologie. Dtsch Med Wochenschr 1982;107:1914-8.

5 Antman E, Muller J, Goldberg S, et al. Nifedipine therapy for coronary-artery spasm. N Engl $\mathcal{f}$ Med 1980;302:1269-73.

6 Delahaye JP, Touboul P, Cassagnes J, Gaspard P, Milon H. The long-term treatment of Prinzmetal's angina with nifedipine. In: Puech $\mathrm{P}, \mathrm{Krebs} \mathrm{R}$, eds. 4th international Adalat ${ }^{R}$ symposium. Amsterdam, Oxford, Princeton: Excerpta Medica, 1980:87-94.

7 Bertrand ME, Lablanche JM, Tilmant PY. Treatment of Prinzmetal's variant angina. Role of medical treatment with nifedipine and surgical coronary revascularisation combined with plexectomy. $A m \mathcal{F}$ Cardiol 1981;47:174-8.

8 Unstable angina pectoris: national cooperative study group to compare surgical and medical therapy. III. Results in patients with S-T segment elevation during pain. Am $\mathcal{F}$ Cardiol 1980;45:819-24.

9 Shubrooks SJ Jr, Bete JM, Hutter AM Jr, et al. Variant angina pectoris: clinical and anatomic spectrum and results of coronary bypass-surgery. $\mathrm{Am} \mathfrak{F} \mathrm{Cardiol}$ 1975;36:142-7.

10 Gaasch WH, Lufschanowski R, Leachman RD, Alexander JK. Surgical management of Prinzmetal's variant angina. Chest 1974;66:614-621.

11 Betriu A, Solignac A, Bourassa MG. The variant form of angina: diagnostic and therapeutic implications. Am Heart $\mathcal{f}$ 1974;87:272-8.

12 Gruentzig AR, Senning A, Siegenthaler WE. Nonoperative dilatation of coronary artery stenosis. Percutaneous transluminal coronary angioplasty. $N$ Engl f Med 1979;301:61-6.

13 Kent KM, Bentivoglio LG, Block PC, et al. Percutaneous transluminal coronary angioplasty: report from the registry of the National Heart, Lung, and Blood Institute. Am F Cardiol 1982;49:2011-20.

14 Levy RJ, Mock MB, Willman VL, Frommer PL. Percutaneous transluminal coronary angioplasty. $N$ Engl f Med 1979;301:101-3.

15 Rafflenbeul W, Lichtlen PR. Zum Konzept der “dynamischen" Koronarstenose. Z Kardiol 1982;71: 439-44.

16 MacAlpin RN. Contribution of dynamic vascular wall thickening to luminal narrowing during coronary arterial constriction. Circulation 1980;61:296-301.

17 Meier B, Gruentzig AR, Goebel N, Pyle R, von Gosslar W, Schlupf $M$. Assessment of stenoses in coronary angioplasty. Inter- and intraobserver variability. Int $\mathcal{F}$ Cardiol 1983;3:159-69.

18 Bentivoglio LG, Leo LR, Wolf NM, Meister SG. Fre- quency and importance of unprovoked coronary spasm in patients with angina pectoris undergoing percutaneous transluminal coronary angioplasty. $\mathrm{Am}$ f Cardiol 1983;51:1067-71.

19 Bertrand ME, Thieuleux FA, Lablanche JM, Cherrier F, Valeix B. Percutaneous transluminal coronary angioplasty (PTCA) in patients with variant angina [Abstract]. Eur Heart $\mathcal{f}$ 1984;5(suppl 1):110.

20 Corcos T, David PR, Bourassa MG, et al. Percutaneous transluminal coronary angioplasty for the treatment of variant angina. $\mathcal{F} \mathrm{Am}$ Coll Cardiol 1985;5:1046-54.

21 Cowley MJ, Dorros G, Kelsey SF, van Raden M, Detre KM. Acute coronary events associated with percutaneous transluminal coronary angioplasty. $\mathrm{Am}$ f Cardiol 1984;53:12C-6C.

22 Cowley MJ, Dorros G, Kelsey SF, van Raden M, Detre KM. Emergency coronary bypass surgery after coronary angioplasty: the National Heart, Lung, and Blood Institute's percutaneous transluminal coronary angioplasty registry experience. $\mathrm{Am} \mathcal{f}$ Cardiol 1984;53:22C-6C.

23 David PR, Waters DD, Scholl JM, et al. Percutaneous transluminal coronary angioplasty in patients with variant angina. Circulation 1982;66:695-702.

24 Leisch F, Herbinger W, Bruecke P. Role of percutaneous transluminal coronary angioplasty in patients with variant angina and coexistant coronary stenosis refractory to maximal medical therapy. Clin Cardiol 1984;7:654-9.

25 Bentivoglio G, van Raden MJ, Kelsey SF, Detre KM. Percutaneous transluminal coronary angioplasty (PTCA) in patients with relative contraindications: results of the National Heart, Lung, and Blood Institute PTCA registry. Am $\mathcal{f}$ Cardiol 1984;53:82C-8C.

26 Kaltenbach M, Kober G, Scherer D, Vallbracht C. Recurrence rate after successful coronary angioplasty. Eur Heart $\mathcal{F} 1985 ; 6: 276-81$.

27 Holmes DR Jr, Vliestra RE, Smith HC, et al. Restenosis after percutaneous transluminal coronary angioplasty (PTCA): a report from the PTCA registry of the National Heart, Lung, and Blood Institute. Am $\mathcal{F}$ Cardiol 1984;53:77C-81C.

28 Leimgruber PP, Roubin GS, Rice CR, Tate JM, Gruentzig AR. Influence of intimal dissection after coronary angioplasty (PTCA) on restenosis rate [Abstract]. Circulation 1984;70(suppl II):II-175.

29 Hollman J, Austin GE, Gruentzig AR, et al. Coronary artery spasm at the site of angioplasty in the first 2 months after successful percutaneous transluminal coronary angioplasty. $\mathcal{F} \mathrm{Am}$ Coll Cardiol 1982;2: 1039-45.

30 Corcos T, David PR, Guitas P, et al. Failure of diltiazem to prevent restenosis after percutaneous transluminal coronary angioplasty. Am Heart $\mathcal{f}$ 1985;109:926-31.

31 Severi S, Davies G, Maseri A, Marzullo P, L'Abbate A. Long-term prognosis of "variant" angina with medical treatment. Am $\mathcal{F}$ Cardiol 1980;46:226-32.

32 Waters DD, Bouchard A, Théroux P. Spontaneous remission is a frequent outcome of variant angina. $f$ Am Coll Cardiol 1983;2:195-9. 